\title{
Hand hygiene in surgery in Benin: opportunities and challenges
}

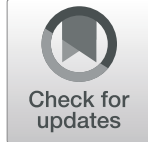

\author{
Carine Laurence Yehouenou ${ }^{1,2,3^{*}} \mathbb{D}$, Angèle Modupe Dohou ${ }^{1,3}$, Ariane Dessièdé Fiogbe ${ }^{1,3}$, Marius Esse ${ }^{2}$, \\ Cyriaque Degbey $^{4,5}$, Anne Simon ${ }^{6,7}$ and Olivia Dalleur ${ }^{1,8}$
}

\begin{abstract}
Background: Hand Hygiene $(\mathrm{HH})$ has been described as the cornerstone and starting point in all infection control. Compliance to $\mathrm{HH}$ is a fundamental quality indicator. The aim of this study was to investigate the $\mathrm{HH}$ compliance among Health-care Workers (HCWs) in Benin surgical care units.

Methods: A multicenter prospective observational study was conducted for two months. The World Health Organization (WHO) Hand Hygiene Observation Tool was used in obstetric and gastrointestinal surgery through six public hospitals in Benin. HH compliance was calculated by dividing the number of times HH was performed by the total number of opportunities. HH technique and duration were also observed.

Results: A total of $1315 \mathrm{HH}$ opportunities were identified during observation period. Overall, the compliance rate was 33.3\% (438/1315), without significant difference between professional categories (nurses =34.2\%; auxiliaries =32.7\%; and physicians $=32.4 \% ; p=0.705)$. However, compliance rates differed $(p<0.001)$ between obstetric $(49.4 \%)$ and gastrointestinal surgery (24.3\%). Generally, HCWs were more compliant after body fluid exposure (54.5\%) and after touching patient (37.5\%), but less before patient contact (25.9\%) and after touching patient surroundings (29.1\%). HCWs were more likely to use soap and water (72.1\%) compared to the alcohol based hand rub solution (27.9\%). For all of the WHO five moments, hand washing was the most preferred action. For instance, hand rub only was observed 3.9\% after body fluid exposure and $16.3 \%$ before aseptic action compared to hand washing at 50.6 and $16.7 \%$ respectively. Duration of $\mathrm{HH}$ performance was not correctly adhered to $94 \%$ of alcohol hand rub cases (mean duration $9 \pm 6 \mathrm{~s}$ instead of 20 to $30 \mathrm{~s}$ ) and $99.5 \%$ of hand washing cases (10 \pm s instead of the recommended 40 to $60 \mathrm{~s}$ ). Of the $432 \mathrm{HCWs}$ observed, $77.3 \%$ followed $\mathrm{HH}$ prerequisites (i.e. no artificial fingernails, no jewellery). We also noted a lack of permanent hand hygiene infrastructures such as sink, soap, towels and clean water.
\end{abstract}

Conclusion: Compliance in surgery was found to be low in Benin hospitals. They missed two opportunities out of three to apply $\mathrm{HH}$ and when $\mathrm{HH}$ was applied, technique and duration were not appropriate. $\mathrm{HH}$ practices should be a priority to improve patient safety in Benin.

Keywords: Hand hygiene, Alcohol based hand rub, Hand washing, Surgery, Observation

\footnotetext{
* Correspondence: yehcarine@yahoo.fr; yehcarine@yahoo.fr

'Clinical Pharmacy Research Group (CLIP), Louvain Drug Research Institute

(LDRI), Université catholique de Louvain UCLouvain, Brussels, Belgium

¿2aboratoire de Référence des Mycobactéries (LRM), Cotonou, Benin

Full list of author information is available at the end of the article
}

(c) The Author(s). 2020 Open Access This article is licensed under a Creative Commons Attribution 4.0 International License, which permits use, sharing, adaptation, distribution and reproduction in any medium or format, as long as you give appropriate credit to the original author(s) and the source, provide a link to the Creative Commons licence, and indicate if changes were made. The images or other third party material in this article are included in the article's Creative Commons licence, unless indicated otherwise in a credit line to the material. If material is not included in the article's Creative Commons licence and your intended use is not permitted by statutory regulation or exceeds the permitted use, you will need to obtain permission directly from the copyright holder. To view a copy of this licence, visit http://creativecommons.org/licenses/by/4.0/. The Creative Commons Public Domain Dedication waiver (http://creativecommons.org/publicdomain/zero/1.0/) applies to the data made available in this article, unless otherwise stated in a credit line to the data. 


\section{Background}

Healthcare-Associated Infections (HAIs) are a major problem for patient safety. They are related to adverse events such as longer hospitalizations, increased antimicrobial resistance, morbidity and mortality, economic and psychological consequences [1]. In developed countries, HAIs affect $5-15 \%$ of hospitalized patients and can reach $9-37 \%$ of those admitted to intensive care units [2]. The situation is more dire in low-income countries where health care systems are often less developed $[3,4]$. HAIs prevention must be a priority as decreasing their incidence [1, 3].

The hands of Healthcare Workers (HCWs) are the most common vehicle for the transmission of microorganisms from patient to patient within the healthcare environment. For instance, Klebsiella Sp, Methicillin Resistant Staphylococcus aureus (MRSA), Clostridium difficile and Gram-negative bacilli are some of the organisms that are likely to be found on HCWs hands [2]. Hand hygiene $(\mathrm{HH}$; i.e. washing hands with soap and water, or disinfection using alcohol based hand rub solution: $\mathrm{ABHR}$ ) is essential to prevent and control HAIs as it reduces microbial colonization and direct transmission from patient to patient $[5,6]$. However, compliance with $\mathrm{HH}$ among HCWs is frequently reported as poor and is usually estimated as less than 50\% [7]. Average compliance with $\mathrm{HH}$ recommendations varies between hospital wards, among professional categories, working conditions as well as according to the definitions used in different studies [8-10].

To promote $\mathrm{HH}$, World Health Organization (WHO) has published "My five moments for hand hygiene", describing the $\mathrm{HH}$ opportunities, which are the moments during healthcare activities when $\mathrm{HH}$ is necessary to interrupt germ transmission by hands: Moment 1- before touching a patient, Moment 2- before clean/ aseptic procedure, Moment 3- after body fluid exposure risk, Moment 4- after touching a patient and Moment 5- after touching patient surroundings $[8,11]$. The compliance to $\mathrm{HH}$ is the proportion of times that $\mathrm{HCWs}$ perform $\mathrm{HH}$ of all five observed opportunities [12]. The WHO and the Centers for Disease Control and Prevention (CDC) recommend that HCWs wash their hands with soap and water, when visible soiling is present for 40 to $60 \mathrm{~s}$. When hands are not visibly soiled, alcohol based hand rub (ABHR) for 20 to $30 \mathrm{~s}$ is recommended [13].

Despite the evidence of benefits of good $\mathrm{HH}$ practices and the relative cost-effectiveness and simplicity of this procedure, compliance remains a challenge, and more so in developing countries [2, 14]. Different factors have been described to influence $\mathrm{HH}$ compliance. For instance, the lack of appropriate infrastructure, the cultural backgrounds and even religious beliefs can play an important role in hindering good practices [15]. The professional category such as doctors, nurses and situations requiring wearing of gowns and gloves can also determine poor $\mathrm{HH}$ compliance [2].

Even tool in obstetric and gastrointestinal surgery exist in Benin, this study is to the best of our knowledge, the first to document the utilization of the WHO $\mathrm{HH}$ observation method [16]. Therefore, the aim of the study was to assess the rate of $\mathrm{HH}$ compliance among $\mathrm{HCWs}$ using the WHO My five moments for hand hygiene tool in obstetric and gastrointestinal surgery.

\section{Methods}

\section{Design and setting}

Direct observation of HCWs during patient care activity by trained and validated observers is recognized as the gold standard for hand hygiene monitoring [12]. We conducted this prospective observational study for 2 months (June-July 2018), at six hospitals in the south of Benin to allow enough time for the collection of 200 opportunities according to the sample size recommended by the WHO.

These hospitals belonged to intermediate (i.e. first reference in the department; Centre hospitalier Universitaire Départemental de l'Ouémé Plateau) and central (i.e. tertiary care; Centre Hospitalier Universitaire Hubert Koutoukou de Maga CNHU, Centre Hospitalier Universitaire de la Mère et de l'Enfant CHUMEL, Bethesda, Centre Hospitalier de zone Suru Lere and Centre Hospitalier Universitaire de Zone d'Abomey-Calavi) level of health care in Benin. Observations were conducted in two selected settings: obstetric (delivery room and ward) and gastrointestinal surgery (operating room and ward).

\section{Participants}

All HCWs (physicians, nurses-auxiliaries, and other HCWs) present in the room were eligible for observation if they provided care to patients. Observations were conducted unobtrusively during routine patient care, mostly during the day but also during the night. HCWs were unaware of being observed to minimize "Hawthorne effect". Additionally, observers did not provide details of the study procedures for HCWs.

\section{Outcomes}

We used the previously validated WHO "My five moments for hand hygiene" observation tool to collect $\mathrm{HH}$ opportunities and calculate the primary outcome: $\mathrm{HH}$ compliance. The term "opportunity" for $\mathrm{HH}$ is defined as a "moment during healthcare activities when $\mathrm{HH}$ is necessary to interrupt germ transmission by hands" [14].

Each application of alcohol hand rub or hand washing with soap and water was regarded as a complied HH opportunity. For instance, any HCW who decontaminated their hands immediately after a contact with a patient 
and then directly attended another patient without touching any object (for example no touching of door handles or any other patients) was considered to have complied with $\mathrm{HH}$ practices in relation to the second patient $[8,14]$.

Secondary outcomes included determinants of compliance, the observation of HCWs adherence to basic $\mathrm{HH}$ parameters such as short clean nails and white tips $<3 \mathrm{~mm}$ long, use of nail polish (bare nails), absence of jewellery (rings, bracelets and watches) and the duration of $\mathrm{HH}$.

\section{Variables and data collection}

To gather the required information, we developed a 3part paper observation grid including: (A) adherence to basic $\mathrm{HH}$ parameters, (B) "My 5 moments for $\mathrm{HH}$ " tool and $(\mathrm{C})$ techniques and duration of $\mathrm{HH}$. Pre-test observation was done out of the study period for 2 days with 2 voluntary nurses in each hospital to calibrate this observation grid.

The observer team was composed of eleven medical students. The author and a specialist of hygiene and infection control, working in one of the six hospitals, previously trained the students. Each observer was allocated to one hospital and one setting (obstetric section or gastrointestinal surgery). Before the beginning of the data collection, observers underwent 1) a 3-day coaching on $\mathrm{HH}$ and the use of the two grids, and 2) a 1-week training in each hospital to familiarize themselves with the infrastructure, the procedures, local HH policy (use of clean water, soap and alcohol) and the personnel.

During the training, we used the WHO training film which describe possible situations during observations sessions. Each observer completed the observational form separately while observing the same $\mathrm{HCW}$ and the same care sequence. Results were then compared and discordant notifications were discussed. This process was repeated until concordance is reached in terms of the number of hand hygiene opportunities and hand hygiene actions that occurred. During the study period, observer team received periodic reinforcement of education (twice per month) focusing on technical issues to conduct observations according to Sax H. method [12].

Trained observers completed one observation grid per observation session. The observation session is a period of $20 \pm 10 \mathrm{~min}$ in a care setting [14]. HCWs could be observed during several sessions. Each $\mathrm{HCW}$ was observed for a maximum of four $\mathrm{HH}$ opportunities during the observed care session according to WHO recommendations [1].

In addition, we used monthly ward infrastructure survey to collect data about infrastructure at ward level. This grid is divided into 28 indicators with questions about resources and facilities for $\mathrm{HH}$ practices such as: sink, water and alcohol, presence or absence of reminders in workplace. At the end of each month, a grid was completed by observers and senior nurses of each hospital. Statistics.

The data were initially recorded on paper and then entered directly into Epidata 3.1. Analysis was done using SPSS version 22 software. Analyses of all variables were conducted overall, and the results presented by frequencies and percentages. Compliance was calculated by dividing the numbers of times hand hygiene was performed by the total number of opportunities.

The chi square test was used to test associations between variables if the expected frequency was above 5 . If the expected frequency below 5, Fisher's exact test was used. In all analyses, $p$ value $\leq 0.05$ was considered to be statistically significant.

\section{Results}

\section{General characteristics}

For 60 days, we observed $432 \mathrm{HCWs}$ around six hospitals $(57.9 \%$ women versus $42.1 \%$ males). Most of them were nurses (55.6\%) and auxiliaries (25.7\%), followed by physicians (13.4\%) and others 5.3\% (i.e. technicians, anesthetists and student physicians or nurses). Table 1 shows the characteristics of observed HCWs.

\section{Hand hygiene compliance and its determinants}

One thousand three hundred fifteen $\mathrm{HH}$ opportunities were observed. The overall $\mathrm{HH}$ compliance was 33.3\% [30.8-CI-35.8], with no significant difference between professional categories. Indeed, compliance was 32.4\% among physicians, $34.2 \%$ among nurses and $25.6 \%$ for other HCWs $(p=0.705)$. The compliance was higher among females than males. ( $40.5 \%$ vs. $26.4 \% p<0.001)$.

In maternity, $\mathrm{HH}$ compliance reached $49.4 \%$ [44.9CI-53.9] while surgery services scored 24.3\% [21.4CI-27.2] $(p<0.001)$. HH compliance before patient contact was $25.2,33.0 \%$ before a clean or aseptic procedure, $37.5 \%$ after patient contact $29.1 \%$ after contact with patient surroundings and $54.5 \%$ after body fluid exposure. The compliance rate did not significantly differ according to the shift $(39.4 \%$ in the afternoon, $32.4 \%$ in the morning, and $50.0 \%$ in the night $p=0.113$ ) (Table 2).

\section{Hand hygiene technique and duration}

When $\mathrm{HH}$ was applied, technique and duration were often not appropriate. Hand washing (HW) remains the most preferred action. Among $438 \mathrm{HH}$ actions, HW was performed in 316 cases $(72.1 \%)$ while ABHR was performed in 122 cases (27.9\%). 0\% used both technics $\mathrm{ABHR}$ and soap and water. After body fluid exposure when hands were visibly soiled, hand washing was performed in $50.6 \%$ of cases while ABHR was for $3.9 \%$. 
Table 1 Characteristics of observed HCWs

\begin{tabular}{llllllll}
\hline Characteristics & Hosp A & Hosp B & Hosp C & Hosp D & Hosp E & Hosp F & Total \\
\hline $\begin{array}{llllll}\text { Professional category } \\
\quad \text { Physicians n (\%) }\end{array}$ & $26(17.5)$ & $1(2.9)$ & $6(9.8)$ & $15(17.6)$ & $4(7.4)$ & $6(12.2)$ & $58(13.4)$ \\
$\quad$ Nurses and auxiliaries n (\%) & $117(78.5)$ & $33(97.1)$ & $42(68.9)$ & $67(78.8)$ & $50(92.6)$ & $42(85.7)$ & $351(81.3)$ \\
$\quad$ Others n (\%) & $6(4.0)$ & $0(0.0)$ & $13(21.3)$ & $3(3.6)$ & $0(0.0)$ & $1(2.0)$ & $23(5.3)$ \\
Total n (\%) & $149(100.0)$ & $34(100.0)$ & $61(100.0)$ & $85(100.0)$ & $54(100.0)$ & $49(100.0)$ & $432(100.0)$ \\
\hline
\end{tabular}

Hosp F=Intermediate level, and the others = central level. A:CNHU-HKM, B:BETHESDA C: CHU-SURU-LERE, D: CHUZ ABOMEY-CALAVI, E: CHUMEL, F: CHUZ PORTO-NOVO.

Before aseptic action and for other moments hand washing was always the first action of compliant HCWs through six hospitals (Fig. 1).

Hand hygiene duration was almost never fully observed by HCWs. $(<6.0 \%$ for ABHR and $0.5 \%$ for hand washing). The median duration for hand washing was $10 \pm 7 \mathrm{~s}$ (instead of 40 to $60 \mathrm{~s}$ ) and $9 \pm 6 \mathrm{~s}$ (instead of 20 to $30 \mathrm{~s}$ ) for ABHR (Table 3).

\section{Adherence to basic hygiene parameters}

The adherence to basic hygiene parameters regarding nails and jewellery among HCWs was higher than the $\mathrm{HH}$ compliance.

In total, more than $77 \%(n=334)$ had their hands free of jewellery and $91 \%(n=393)$ of them had natural short and without polish fingernails. Only $1.8 \%(n=8)$ of healthcare professionals had nails extensions.

Table 2 Hand hygiene compliance among HCWs in Benin

\begin{tabular}{|c|c|c|c|c|}
\hline Characteristics & Hand Hygiene opportunities (n) & Hand Hygiene actions $\left(n^{a}\right)$ & $\%$ Compliance & $P$ value \\
\hline Overall Wards & 1315 & 438 & 33.3 & \\
\hline Surgery visceral & 841 & 204 & 24.3 & $P<0.001$ \\
\hline Maternity & 474 & 234 & 49.4 & \\
\hline \multicolumn{5}{|c|}{ Professional category } \\
\hline Physician & 139 & 45 & 32.4 & $P=.705$ \\
\hline Nurses & 752 & 257 & 34.2 & \\
\hline Auxiliary nurse & 385 & 126 & 32.7 & \\
\hline Others & 39 & 10 & 25.6 & \\
\hline \multicolumn{5}{|l|}{ Sex } \\
\hline Male & 671 & 177 & 26.4 & $P<0.001$ \\
\hline Female & 644 & 261 & 40.5 & \\
\hline \multicolumn{5}{|l|}{ Shift } \\
\hline Morning & 1161 & 376 & 32.4 & $P=.113$ \\
\hline Afternoon & 142 & 56 & 39.4 & \\
\hline Night & 12 & 6 & 50.0 & \\
\hline \multicolumn{5}{|c|}{ WHO five moments } \\
\hline Moment 1 & 393 & 99 & 25.2 & $P<0.001$ \\
\hline Moment 2 & 209 & 69 & 33.0 & \\
\hline Moment 3 & 77 & 42 & 54.5 & \\
\hline Moment 4 & 509 & 191 & 37.5 & \\
\hline Moment 5 & 127 & 37 & 29.1 & \\
\hline \multicolumn{5}{|l|}{ Care room } \\
\hline Bandage area & 571 & 267 & 46.8 & $P<0.001$ \\
\hline Hospitalization & 691 & 139 & 20.1 & \\
\hline Others & 53 & 32 & 60.4 & \\
\hline
\end{tabular}

Five moments: 1-before touching patient, 2-Before clean/aseptic procedure, 3-after body fluid exposure risk, 4-after touching a patient, 5-after touching patient surroundings. 
$\square \mathrm{HW}(\%) \quad \square \mathrm{ABHR}(\%)$

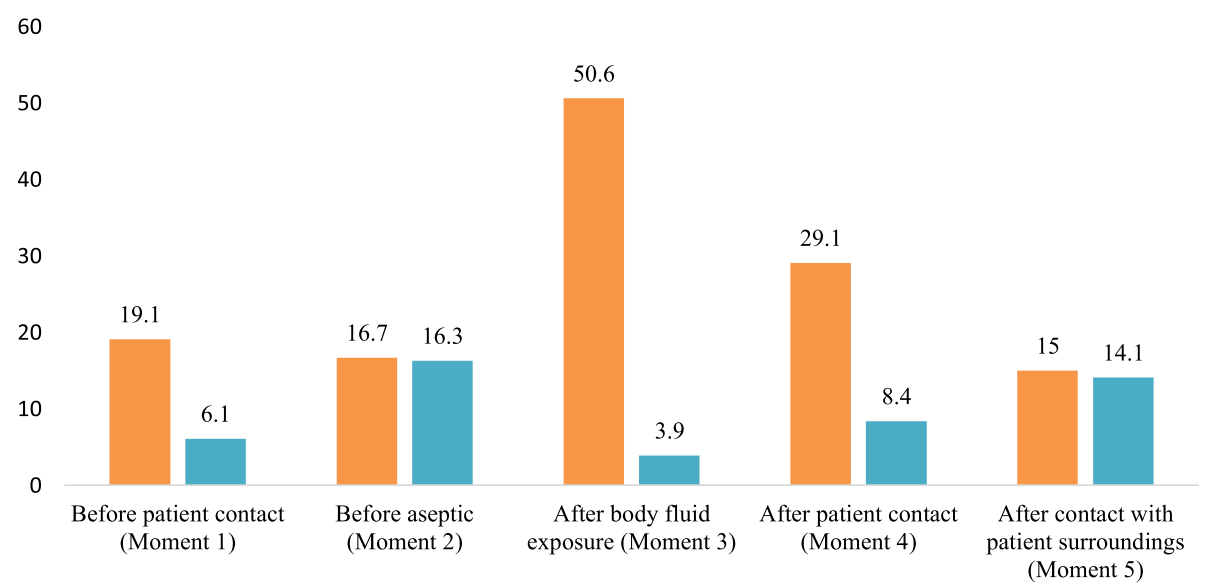

Fig. 1 Hand hygiene actions by indications among HCWs (Benin 2018)

\section{Hand hygiene infrastructures}

Clean water and alcohol based hand rub was only available half of time in all of six hospitals, sinks were often inconveniently located: out of the patient room or the point of care. None of the hospitals provided single-use towels. Only two hospitals displayed WHO posters explaining correct use of hand rub and handwashing technique. Observed hospitals did not organize training sessions about $\mathrm{HH}$ for HCWs. (Table 4) summarizes $\mathrm{HH}$ infrastructures for six hospitals.

\section{Discussion}

Hand hygiene is one of the foremost techniques to reduce HAIs [17]. However, overall $\mathrm{HH}$ compliance was $33.3 \%$ in this observational study. The behavior of HCWs showed a tendency towards self-protection, that is, with a higher compliance rate after body fluid exposure risk and after patient contact than before touching patient. The adherence to $\mathrm{HH}$ parameters regarding hair, nails and the use of jewellery was better than over all compliance. $\mathrm{HH}$ infrastructures were deficient or inconstantly present at the point of care. This multicenter observational study is the first in Benin which assessed $\mathrm{HH}$ compliance according to $\mathrm{WHO}$ recommendations.

Table 3 Hand hygiene duration among compliant HCWs in June-July 2018

\begin{tabular}{lll}
\hline Hand Hygiene Duration & Frequency $(n)$ & Percentage (\%) \\
\hline $\begin{array}{l}\text { Wash duration in } \\
\text { seconds (s) }\end{array}$ & Median washing $(10 \pm 7)$ & \\
Less than 40 & 199 & 99.5 \\
More than 40 & 1 & 0.5 \\
Alcohol rub duration (s) & Median ABHR $(9 \pm 6)$ & \\
Less than 20 & 78 & 94.0 \\
More than 20 & 5 & 6.0 \\
\hline
\end{tabular}

However, this also makes it difficult to compare our results with prior findings.

Overall $\mathrm{HH}$ compliance was lower (33.3\%) than findings of authors from Nigeria (65.3\%), Brazil (46.7\%) and Saudi Arabia (50.3\%) [18]. Hand hygiene compliance seems better in maternity care room. The possible reason might due to the possible regular availability of water and washing agents in maternity compared to the gastrointestinal surgery. Luangasanatip et al. found in a systematic review and network meta-analysis of 41 hand hygiene studies that baseline compliance with $\mathrm{HH}$ among HCWs was on average only $38.7 \%$ [19] . A $24 \mathrm{~h}$ observational study in Ethiopia showed lower (22.0\%) compliance rates than in our study but they collected less opportunities than in our study [4]. In Benin, the WHO's multimodal hand hygiene improvement strategy is not implemented yet [20]. Many studies suggest that $\mathrm{HH}$ intervention such as the multimodal strategy of WHO has a great potential to improve HCW compliance $[18,21]$.

The compliance was low across all professional categories. However, nurses tend to be more compliant than auxiliary nurses and physicians $(P=0.705)$. This observation is concordant with the findings of other studies $[22,23]$. In the literature, compliance with $\mathrm{HH}$ among nurses are better than doctors $[24,25]$. In a multicenter study done in 5 countries (Costa Rica, Italy, Mali, Pakistan and Saudi Arabia), physicians had the lowest and the nurses had the highest compliance except for Mali [8]. The lower compliance among physicians could be explained by the absence of a team leader acting as a role model for other colleagues [26]. Medical students reported feeling strongly influenced by negative role models thereby abstaining from compliance with $\mathrm{HH}$ guidelines [27]. Erasmus et al. showed that physicians seem to be skeptical or less convinced than other 
Table 4 Hand hygiene infrastructures in six hospitals, 2018

\begin{tabular}{|c|c|c|c|c|c|c|}
\hline Characteristics & Hosp A & Hosp B & Hosp C & Hosp D & Hosp E & Hosp F \\
\hline Is Running water available & A & I & I & I & I & 1 \\
\hline Is water visibly clean & Yes & Yes & Yes & Yes & Yes & Yes \\
\hline Kind of taps available & Hand- Operated & Hand-operated & Hand-operated & Hand-operated & Hand-operated & Hand-operated \\
\hline Are disposable towels available at all sinks & No & No & No & No & No & No \\
\hline Is soap available at all sinks & । & Yes & Yes & Yes & Yes & । \\
\hline Is an ABHR available (\%) & 100 & 50 & 50 & 100 & 50 & 50 \\
\hline $\begin{array}{l}\text { Are posters illustrating } \mathrm{HH} \text { technique beside } \\
\text { each sink }\end{array}$ & No & No & Yes & No & Yes & No \\
\hline $\begin{array}{l}\text { Is any other type of reminder on } \mathrm{HH} \text { available } \\
\text { on this ward? }\end{array}$ & No & No & No & No & No & No \\
\hline $\begin{array}{l}\text { Are audits on } \mathrm{HH} \text { compliance periodically } \\
\text { performed? }\end{array}$ & No & No & No & No & No & No \\
\hline
\end{tabular}

I Intermittently = Unavailability half of time. ABHR Alcohol based Hand Rub, A Always

professional categories about the effectiveness of $\mathrm{HH}$ to reduce HAI or to limit the spread of antimicrobial resistance and improve patient safety $[27,28]$. Some studies even suggested turning nurses into ambassadors of hand hygiene programs $[29,30]$. In most of the cases, nurses are aware of the rationale for hand hygiene procedures and represent a large working group that performs the greatest amount of direct patient care. If nurse behavior can change, the impact on the healthcare system will be significant [31]. Clearly, there is a need to develop strategies to improve physician's compliance [17]. In our setting for instance the best way will to implement in physicians 7 years cursus, hand hygiene courses. No study has been undertaken in Benin about the importance of including $\mathrm{HH}$ program in the curriculum. But it has been done elsewhere. For instance Chakravarthy et al. found that "the knowledge levels of medical students about $\mathrm{HH}$ is far below expectations; the administrators should take upon themselves to include this topic in the educational curriculum" [32].

The compliance was low before patient contact (25.2\%) and after contact with patient surroundings (29.1\%). Dancer et al. argue that environmental cleaning needs to be improved generally and specifically at hand touch sites [33]. Hand touch sites with the highest risk to patients are those which are next to the patient, for example, bedrails, lockers, over beds tables and door handles [33, 34]. Carling et al. found that more than half of the inanimate objects such as those previously listed were not microbiologically clean when screened [35]. By contrast, HCWs were more compliant after body fluid exposure and after patient contact $(p<0.001)$. This finding is in line with an observational study in Kuwaiti hospitals that suggested that $\mathrm{HCW}$ s perform $\mathrm{HH}$ for their own protection, rather than to protect their patients [36]. Self-protection tendency has been identified in multiple studies [36, 37].
Despite recommendation of the Centers for Disease Control (CDC) and WHO guidelines on $\mathrm{HH}$ in healthcare to use ABHR solution as the preferred means for routine hand hygiene [21, 38], its use remains poor. Among 438 HH actions, only 122 (27.9\%) used alcohol based hand rub solution while 316 (72.1\%) performed hand washing. This finding could be explained by lack of knowledge concerning its benefits, and also lack of infrastructure in our hospitals. Moreover, the few HCWs who washed their hands, did so inefficiently. The median time for hand rubbing was $9 \mathrm{~s}$ and only $6 \%$ respected the correct time. There was no gain in reducing bacterial counts from hand rubbing longer than 30 but a $30 \mathrm{~s}$ application is usually sufficient [39]. By contrast, the median time for hand washing was $10 \mathrm{~s}$ and $0.5 \%$ respected the correct duration. Reported reasons for not respecting $\mathrm{HH}$ duration and technique include too many opportunities per hour, or simply ignorance of guidelines or forgetfulness [7,29,40].

Unfortunately $22.7 \%$ of the HCWs still use long natural, polished or artificial fingernails when caring patients. This is strongly discouraged by the WHO because the majority of flora on the hands are found under and around the fingernails [13]. Artificial and long polished nail harbor harmful bacteria and studies described difficulty in their elimination with cleaning. Alcohol-based hand rub solution cleared pathogens from both artificial and natural nails better than antimicrobial soap $[41,42]$. However, jewellery must be kept to a minimum. Jeweled rings or rings with stones should not be worn, a plain wedding ring is permitted [43].

There are serious barriers to compliance in the observed hospitals. For instance, the compliance rate was particularly low ( $20 \%$ vs $46,8 \% ; p<0.01)$ in hospitalization rooms compared to the bandage room where we can intermittently find sinks and other infrastructures. By contrast, in all of 6 hospitals, supplies were not placed at key location throughout patient room. Absence or irregularity of $\mathrm{HH}$ supplies 
can sometimes discourage personal to wash their hands when indicated [23]. Limited access to hand hygiene supplies such as soap or alcohol hand rub solutions are challenges compliance [23]. Cantrell et al. found a positive correlation between compliance rates and the presence of a sink in the patient's room [44]. In addition, there were no poster and other visual reminders for $\mathrm{HH}$ at work in some hospitals which may help increase compliance. The present audit is the first one in all of these hospitals, making it very important for future hospital planning, management and patient safety. Successful promotion of hand hygiene strategies (e.g., making hand hygiene products available at the point of care, allocate special budget for $\mathrm{HH}$, improvement of $\mathrm{HH}$ education among $\mathrm{HCWs}$ ) should be considered in all of these hospitals.

\section{Strengths and limitations}

The main strength of this study is the settings: it is the first study to document the utilization of the WHO $\mathrm{HH}$ observational method. Moreover, it included two wards in six different hospitals. Despite the limited numbers of observations during the night shift and weekends and the fact that data collection did not record the use of gloves, this study provides HCWs with reliable information about $\mathrm{HH}$ practice in Benin. The present study was conducted using direct observation method, the most reliable method for measuring the rate of adherence to $\mathrm{HH}$ [45]. Observers were trained and used validated data collection forms. A potential bias associated with observation is called the "Hawthorne effect". HCWs have opportunities to change their behavior when they know that they are being observed [46]. So, they were not aware they were being observed to diminish this effect.

This study was the first step of MUltidisciplinary STrategy for Prevention and Infection Control (MUSTPIC) project. This project aims to increase HCWs compliance by implementation of WHO Multimodal Strategy which includes 5 keys components: system changes, HCWs training and education, evaluation and feedback, reminders in the workplace, and promotion of an institutional safety climate. Next steps include a qualitative assessment of factors underlying $\mathrm{HH}$ compliance with interviews among HCWs.

\section{Conclusion}

This study showed a poor HH compliance among different HCWs in surgery in Benin. As $\mathrm{HH}$ is an influential and cost-effective way of reducing HAIs, it should become an educational priority in Benin health care settings with the promotion of the WHO multimodal hand hygiene strategy: "Hand care is safer care". Access to HH resources should be emphasized as an integral part of $\mathrm{HH}$ improvement strategy.

\section{Abbreviations}

HCWs: Health care workers; WHO: World health organization;

HAls: Healthcare associated infections; $\mathrm{HH}$ : Hand hygiene; HHO: Hand hygiene opportunities; ABHR: Alcohol based hand rub; Cl: Confidence interval; HW: Hand washing

\section{Acknowledgements}

The authors thank all healthcare workers for their cooperation and all observer teams for their assistance in this study.

\section{Authors' contributions}

CLY: Study design, facilitation of data collection, data analysis and drafting the manuscript, OD and AS: Conception of the idea, Study design, revising the manuscript, $A M D$ and $A F$ : supervision of observation team, revising the manuscript, DC: Hand Hygiene observation grid and manuscript revising, EM: statistical analysis and revising the manuscript All authors read and approved the last version.

\section{Funding}

The study was conducted with funding provided by Académie de la Recherche pour l'Enseignement Supérieur (ARES) with the convention number: CCOP-CONV-18-108.

\section{Availability of data and materials}

The data supporting the results of this study are included within the article and its additional files.

\section{Ethics approval and consent to participate}

The study protocol was approved by the ethical committee of Medical Science of Medicine Faculty (FSS). Acceptance letter and convention letter was obtained from each hospital director. Information on the study was explained to the participants, including procedures, potential risks and benefits of the study. Confidentiality was maintained at all levels of the study by avoiding use of name and other identifiers.

\section{Consent for publication}

Not-applicable.

\section{Competing interests}

The authors declare there are no conflict of interests.

\section{Author details}

'Clinical Pharmacy Research Group (CLIP), Louvain Drug Research Institute (LDRI), Université catholique de Louvain UCLouvain, Brussels, Belgium.

${ }^{2}$ Laboratoire de Référence des Mycobactéries (LRM), Cotonou, Benin. ${ }^{3}$ Faculte des Sciences de la Sante (FSS), Université d'Abomey Calavi (UAC), Cotonou, Benin O3BP1326. ${ }^{4}$ Institut Régional de Santé Publique Comlan Alfred Quenum (IRSP), Ouidah, Benin. ${ }^{5}$ Clinique Universitaire d'Hygiène Hospitalière, Centre National Hospitalo-universitaire Hubert Koutoukou Maga, Cotonou, Benin. ${ }^{6}$ Pole de microbiologie, Institut de Recherche Expérimentale et Clinique (IREC), Université catholique de Louvain UCLouvain, Brussels, Belgium. ${ }^{7}$ Microbiologie, Cliniques universitaires Saint-Luc, Université catholique de Louvain, UCLouvain, Brussels, Belgium. ${ }^{8}$ Pharmacy, Cliniques universitaires Saint-Luc, Université catholique de Louvain, UCLouvain, Brussels, Belgium.

Received: 24 July 2019 Accepted: 4 June 2020

Published online: 15 June 2020

References

1. Organisation mondiale de la santé. Résumé des Recommandations de I'OMS pour l'Hygiène des Mains au cours des Soins. 2010;1-3,5,18.

2. Allegranzi B, Pittet $D$. Role of hand hygiene in healthcare-associated infection prevention. J Hosp Infect. 2009;73:305-15.

3. Asare A, Enweronu-Laryea CC, Newman MJ. Hand hygiene practices in a neonatal intensive care unit in Ghana. J Infect Dev Ctries. 2009:3:352-6.

4. Kolola T, Gezahegn T. A twenty-four-hour observational study of hand hygiene compliance among health-care workers in Debre Berhan referral hospital, Ethiopia. Antimicrobial Resist Infec Control. 2017;6:1-5.

5. Khan HA, Baig FK, Mehboob R. Nosocomial infections: epidemiology, prevention, control and surveillance. Asian Pac J Trop Biomed. 2017;7:478-82. 
6. Duerink DO, Farida H, Nagelkerke NJ, Wahyono H, Keuter M, Lestari ES, et al. Preventing nosocomial infections: improving compliance with standard precautions in an Indonesian teaching hospital. J Hosp Infect. 2006;64:36-43.

7. Pittet D. Improving adherence to hand hygiene practice: a multidisciplinary approach. Emerg Infect Dis. 2001;7:234-40.

8. Allegranzi B, Gayet-Ageron A, Damani N, Bengaly L, McLaws ML, Moro ML, et al. Global implementation of WHO's multimodal strategy for improvement of hand hygiene: a quasi-experimental study. Lancet Infect Dis. 2013;13:843-51.

9. Pittet D. Hand hygiene: from research to action. J Infect Prev. 2017;18:100-2.

10. Oh HS. Knowledge, perception and self-reported performance of hand hygiene among registered nurses at community- based hospitals in Republic of Korea: a cross-sectional multi-Centre study. J Prev Med Public Health. 2018;51:121-9.

11. World Health Organization (WHO). Hand Hygiene Technical Reference Manual: To be used by health-care workers, trainers and observers of hand hygiene practices. Geneva: WHO; 2009. p. 1-31.

12. Salmon S, Pittet D, Sax H, McLaws ML. The 'My five moments for hand hygiene' concept for the overcrowded setting in resource-limited healthcare systems. J Hosp Infect. 2015;91:95-9.

13. World Health Organization (WHO). WHO save lives: clean yours hands 5 May 2019. Clean care for all-it's in your hands. 2019. Available from: http://www. who.int/infection-prevention/en/.pdf.

14. Kilpatrick C, Allegranzi B, Pittet D. WHO fist global patient safety: clean care is safer care: contributing to the training of health care workers around the globe. Int J Infect Control. 2011;7(2):1-8.

15. Ahmed QA, Memish ZA, Allegranzi B, Pittet D. Muslim health-care workers and alcohol-based handrubs. Lancet. 2006:367:1025-7.

16. Ahoyo TA, Bankolé HS, Adéoti FM, Gbohoun AA, Assavèdo S, AmoussouGuénou $\mathrm{M}$, et al. Prevalence of nosocomial infections and anti-infective therapy in Benin: results of the first nationwide survey in 2012. Antimicrob Resist Infect Control. 2014:3:2-7.

17. Buffet-Bataillon S, Leray E, Poisson M, Michelet C, Bonnaure-Mallet M, Cormier M. Influence of job seniority, hand hygiene education, and patientto-nurse ratio on hand disinfection compliance. J Hosp Infect. 2010;76:32-5.

18. Uneke CJ, Ndukwe CD, Oyibo PG, Nwakpu KO, Nnabu RC, Prasopa-Plaizier N Promotion of hand hygiene strengthening initiative in a Nigerian teaching hospital: implication for improved patient safety in low-income health facilities. Braz J Infect Dis. 2014;18:21-7.

19. Luangasanatip N, Hongsuwan M, Limmathurotsakul D, Lubell Y, Lee AS, Harbarth S, et al. Comparative efficacy of interventions to promote hand hygiene in hospital. Syst Rev Netw Metaanal. 2015;28(351):h3728. https://doi. org/10.1136/bmj.h3728.

20. Rodriguez V, Giuffre C, Villa S, Almada G, Prasopa-Plaizier N, Gogna M, et al. A multimodal intervention to improve hand hygiene in ICUs in Buenos Aires, Argentina: a stepped wedge trial. Int J Qual Health Care. 2015;27:405-11.

21. Mazi W, Senok AC, Al-Kahldy S, Abdullah D. Implementation of the world health organization hand hygiene improvement strategy in critical care units. Antimicrob Resist Infect Control. 2014;2(1):15

22. Sakihama T, Honda H, Saint S, Fowler KE, Kamiya T, Sato Y, et al. Improving healthcare workers hand hygiene adherence before patient contact: a multimodal intervention of hand hygiene practice in three Japanese tertiary care centers.J Hosp Med. 2016:11:199-205.

23. Hugonnet S, Pittet D. Hand hygiene - beliefs or science? Clin Microbiol infect. Eur Soc Clin Infect Dis. 2000;6(7):384-54

24. Karaaslan A, Kepenekli Kadayifci E, Atici S, Sili U, Soysal A, Culha G, et al. Compliance of healthcare workers with hand hygiene practices in neonatal and pediatric intensive care units: overt observation. Interdiscip Perspect Infect Dis. 2014:2014:306478.

25. Muller MP, Carter E, Siddiqui N, Larson E. Hand hygiene compliance in an emergency department: the effect of crowding. Acad Emerg Med. 2015;22:1218-21.

26. Azim S, Juergens C, McLaws ML. An average hand hygiene day for nurses and physicians: the burden is not equal. Am J Infect Control. 2016;44:777-81.

27. Erasmus V, Brouwer W, van Beeck EF, Oenema A, Daha TJ, Richardus JH, et al. A qualitative exploration of reasons for poor hand hygiene among hospital workers lack of positive role models and of convincing evidence that hand hygiene prevents cross-infection. Infect Control Hosp Epidemiol. 2009:30:415-9.

28. Modi PD, Kumar P, Solanki R, Modi J, Chandramani S, Gill N. Hand hygiene practices among indian medical undergraduates: a questionnaire-based survey. Cureus. 2017;9(7):e1463.
29. Goldmann D. System failure versus personal accountability - the case for clean hands. N Engl J Med. 2006;355:121-3.

30. Shobowale EO, Onyedibe KI, Adegunle KB, Elikwu CJ. An observational and trend analysis study of hand hygiene practices of healthcare Workers at a Private Nigerian Tertiary Hospital. Ann Med Health Sci Res. 2017;7:84-9.

31. Malliarou M, Zyga S, Theodoros C, Constantidinis TC, Sarafis P. The importance of nurses hand hygiene. Int J Caring Sci. 2013;6:327-31.

32. Prabhakumar D, Chakravarthy M, Nayak S, Hosur R, Padgaonkar S, Harivelam C, et al. Knowledge levels of medical students about hand hygiene. J Natl Accredit Board Hosp Healthc Provid. 2016;3:27.

33. Pittet D. Healthcare-associated infection: moving behind headlines to clinical solutions. J Hosp infect. The Hospital Infection Society. 2009;73:293-5.

34. Dancer SJ. The role of environmental cleaning in the control of hospitalacquired infection. J Hosp Infect. 2009;73:378-85.

35. Carling PC, Bartley JM. Evaluating hygienic cleaning in health care settings: what you do not know can harm patients. Am J Infect Control. 2010;38: S41-50.

36. Salama MF, Jamal WY, Mousa HA, Al-AbdulGhani KA, Rotimi VO. The effect of hand hygiene compliance on hospital-acquired infections in an ICU setting in a Kuwaiti teaching hospital. J Infect Public Health. 2013;6:27-34.

37. Brackett $A$. Understanding healthcare staff's hand hygiene adherence: a theory-driven approach. 2016; Available from: https://ra.le.ac.uk/handle/23 $81 / 38219$

38. Pires D, Bellissimo-Rodriques F, Soule $H$, Gayet-Ageron A, Pittet D. Revisiting the WHO how to handrub hand hygiene technique: fingertips first? Infect Control Hosp Epidemiol. 2017:38(2):230-3.

39. Pires D, Soule H, Bellissimo-Rodrigues F, Gayet-Ageron A, Pittet D. Hand hygiene with alcohol-based hand rub: how long is long enough? Infect Control Hosp Epidemiol. 2017;38:547-52.

40. Bowen $\mathrm{A}, \mathrm{Ma} \mathrm{H}, \mathrm{Ou} \mathrm{J}$, Billhimer W, Long T, Mintz E, et al. A clusterrandomized controlled trial evaluating the effect of a handwashingpromotion program in Chinese primary schools. Am J Trop Med Hyg. 2007:76:1166-73.

41. Arrowsmith VA, Taylor R. Removal of nail polish and finger rings to prevent surgical infection. Cochrane Database Syst Rev. 2014;4(8):CD 003325.

42. McNeil SA, Foster CL, Hedderwick SA, Kauffman CA. Effect of hand cleansing with antimicrobial soap or alcohol-based gel on microbial colonization of artificial fingernails worn by health care workers. Clin Infect Dis. 2001;32: $367-72$.

43. Al-Allak A, Sarasin S, Key S, Morris-Stiff G. Wedding rings are not a significant source of bacterial contamination following surgical scrubbing. Ann R Coll Surg Engl. 2008;90:133-5.

44. Cantrell D, Shamriz O, Cohen MJ, Stern Z, Block C, Brezis M. Hand hygiene compliance by physicians ; marked heterogeneity due to local culture? Can we improve? Am J Infect Control. 2009;37(4):301-5.

45. Magnus TP, Marra AR, Camargo TZS, Victor Eda S, da Costa LS, Cardoso VJ, et al. Measuring hand hygiene compliance rates in different special care settings: a comparative study of methodologies. Int J Infect Dis. 2015;33: 205-8.

46. Chang NCN, Reisinger HS, Jesson AR, Schweizer ML, Morgan DJ, Forrest GN, et al. Feasibility of monitoring compliance to the my 5 moments and entry/ exit hand hygiene methods in US hospitals. Am J Infect Control. 2016;44: $938-40$.

\section{Publisher's Note}

Springer Nature remains neutral with regard to jurisdictional claims in published maps and institutional affiliations.

\section{Ready to submit your research? Choose BMC and benefit from:}

- fast, convenient online submission

- thorough peer review by experienced researchers in your field

- rapid publication on acceptance

- support for research data, including large and complex data types

- gold Open Access which fosters wider collaboration and increased citations

- maximum visibility for your research: over $100 \mathrm{M}$ website views per year

At $\mathrm{BMC}$, research is always in progress.

Learn more biomedcentral.com/submissions 